\title{
A process for developing an e-health standards selection method artefact using design science research
}

\author{
Funmi Adebesin* \\ Department of Informatics, University of Pretoria, Private Bag X20, Hatfield, 0028, \\ South Africa \\ Email: funmi.adebesin@up.ac.za \\ *Corresponding author
}

\section{Paula Kotzé}

CSIR Meraka Institute, P.O. Box 395, Pretoria, 0001, South Africa

and

Department of Informatics, University of Pretoria, Private Bag X20, Hatfield, 0028, South Africa

Email: paula.kotze@meraka.org.za

\begin{abstract}
The use of design science research (DSR) as a paradigm of choice among information systems (IS) researchers is growing. While there is an apparent increase in the number of DSR artefacts of the method form, very few research publications provide details of the process followed to create such method artefacts in and of itself. Even rarer is the use of the DSR paradigm in e-health research. In this paper, we present the process followed to develop a DSR method artefact, called the standards selection method for e-health interoperability (SMeHI). SMeHI is a generic method that guides the selection of e-health standards to support interoperability between healthcare IS. The development of the method was motivated by the World Health Organisation's (WHO's) call in 2014 for guidance to lower and middle income countries, many of which are African countries, on how to decide on standards to adopt at national level.
\end{abstract}

Keywords: artefacts; design science research; DSR; e-health; interoperability; method; standards.

Biographical notes: Funmi Adebesin is a Senior Lecturer at the Department of Informatics, University of Pretoria, South Africa. She holds a PhD in Information Technology from the Nelson Mandela University, which she obtained in 2015. Her research focuses on e-health systems and their interoperability, use of mobile and wearable health devices to promote personal well-being, as well as the usability and user experience of e-health systems. 
Paula Kotzé is a chief researcher at the Meraka Institute of the Council for Scientific and Industrial Research (CSIR) in South Africa, where she focuses on enterprise systems engineering and socio-technical systems. She is also an Extraordinary Professor at the Department of Informatics at University of Pretoria and the School of ICT at Nelson Mandela University. Her background is multidisciplinary combining computer science, information systems, industrial psychology, human-computer interaction and education. She is a specialist in human factors engineering, enterprise architecture and enterprise systems engineering, design thinking, design research and health informatics, as reflected in an extensive publication record. She holds a $\mathrm{PhD}$ in Computer Science with specialisation in Human-Computer Interaction from the University of York, UK, which she obtained in 1997.

\section{Introduction}

Design science research (DSR) aims to change the state-of-the-world by enabling the generation of knowledge through the process of constructing novel artefacts (Vaishnavi and Kuechler, 2015). As such, DSR is a problem-solving research strategy aimed at creating socio-technical artefacts to address and better understand a given problem in a given context.

The typical types of artefacts developed in DSR are constructs, models, methods, frameworks, instantiations and better theories (Hevner and Chatterjee, 2010; Hevner et al., 2004; Kotzé et al., 2015; March and Smith, 1995; Vaishnavi and Kuechler, 2015; Verbrugge, 2016) (see Section 2.2.2 for more detail on the types of artefacts). This paper focuses on the development of method artefacts. A method can be described as the set of steps or a systematic approach to carry out a specific task (Verbrugge, 2016).

The use of DSR as a suitable research approach in information systems (IS) research is on the increase (Myers and Venable, 2014). The focus of this paper is on specific instances of IS in the healthcare domain, namely e-health systems such as electronic medical record (EMR) systems.

In the early years of the emergence of DSR in the IS field, most of the artefacts generated were in the form of models, constructs or instantiations. The small number of DSR efforts that produced method artefacts was limited to the construction and evaluation of algorithms or mathematical/statistical techniques (Bucher and Winter, 2008). This trend has changed in recent years, with a significant increase in the number of the 'method' form of DSR outputs. For example, Ayanso et al. (2011), in their analysis of 48 DSR-related publications in the field of database management research in three journals Information Systems Research (1990 to 2007), Journal of Management Information Systems (1984 to 2007) and MIS Quarterly (1977 to 2007) found that 26 outputs were classified as methods, 12 as models, seven as instantiations, and the remaining three as constructs. Likewise, Amrollahi et al. (2014), in their analysis of 72 research papers from 14 premier IS journals, found that $49 \%$ of the outputs were in the form of method artefacts. Many of these publications focused on how to address organisational/business problems, such as customer relationship management, IT investment decision processes, application portfolio management, etc.

However, despite an apparent increase in the number of publications on DSR method artefacts, our review of the literature indicated a paucity of publications detailing the 
process followed to create the method artefacts, in and of itself. Even rarer than literature on details on the process followed to create method artefacts, is publications on the use of the DSR approach in e-health research (Lehto, 2012).

The main objective of this paper is to address this paucity by explicitly describing the DSR process followed in developing a method artefact in the e-health domain. The purpose of the resulting method artefact is to guide the selection of e-health standards to support interoperability among healthcare systems/applications. The development of the method was motivated by the World Health Organisation's (WHO's) call in 2014 for guidance to lower and middle income countries, many of which are African countries, on how to decide on standards to adopt at national level (WHO, 2014).

The method artefact, called the standards selection method for e-health interoperability (SMeHI), has as target audience government agencies in Africa that are responsible for making recommendations on e-health standards to adopt at local, regional or national level.

Section 2 provides a broad overview of the nature of DSR, two previous studies on method development and background to the context for which SMeHI is developed. Section 3 details the process followed to develop SMeHI. Section 4 reflects on the work completed and the context thereof in relation to other research/development. Section 5 concludes the paper.

\section{Background}

Section 2.1 provides a brief overview of the context for which the method was developed. Section 2.2 provides an overview of the nature of DSR, including typical DSR artefact outputs, an overview of the DSR process used in developing the method artefact, typical artefact evaluation approaches, and distinctive knowledge contributions in DSR. In Section 2.3, two examples of past research/development of method artefacts are presented, one using DSR and the second an example from the standardisation domain.

\subsection{Background to African context}

Many African countries are confronted with a high level of burden of disease, including HIV/AIDS, tuberculosis and other chronic or non-communicable diseases. E-health is seen as a catalyst of addressing many of the continent's healthcare challenges, but taking advantage of e-health's benefits has been slow and disconnected. One of the reasons for this is that e-health system implementations are hardly ever coordinated at national level, but driven by donor-funded vertical programs (e.g., HIV/AIDS monitoring and evaluation). These implementations are almost always pilot projects inside one health facility with no evidence of scaling up (Adebesin et al., 2013).

However, in African countries where EMR systems have been implemented (e.g., South Africa), the vast majority of such systems lack the capability of sharing vital health information to support continuity of care (NDoH and CSIR, 2014). The full potential of e-health investments cannot be realised when healthcare information systems (HISs) are not interoperable and lack the ability to share vital health information about patients (ITU, 2012). Lack of interoperability between healthcare systems hinders effective healthcare coordination and could potentially endanger patients' lives. 
The important role of standardisation in ensuring interoperability is well documented (Atalag et al., 2010; ITU, 2012; Serrano-Santoyo and Rojas-Mendizabal, 2014; WHO and ITU, 2012). E-health standards adoption at national level in many African countries is, however, limited to the International classification of diseases (ICD-10) codes (WHO, 2016b). It has been found that there is close relationship between the inability of e-health systems to share health information and the low level of e-health standards adoption at national level in many African countries (Adebesin et al., 2013). One of the reasons for this is lack of skills and expertise in Africa in the field of e-health standardisation.

Concerns over the fragmentation of healthcare systems have also dominated global discourse of healthcare stakeholders in recent years. For example, the World Health Organization (WHO) has convened two fora on eHealth Standardization and Interoperability (in 2012 and 2014) to promote the interoperability of HISs through the adoption of appropriate standards at national level (WHO, 2012, 2014). In 2014, the WHO called for guidance to low and medium income countries (LMICs) on how to decide on standards to adopt.

Deciding on the set of standards to adopt is quite complex (Atalag et al., 2010; Bender and Sartipi, 2013). This is partly due to the large number of published e-health standards (eHealth Ontario, 2013).

Although many developed countries across the globe are embarking on initiatives to adopt e-health standards to address the problem of interoperability at national level, the approaches such countries follow to decide on the standards to adopt are often not documented or publicly available. The few approaches that are publicly available (see Section 3.2.4) vary in nature. Furthermore, the approaches followed by developed countries may not necessarily be suitable for African countries, a situation which is compounded by the lack of skills and expertise in e-health standardisation.

\subsection{The nature of DSR}

\subsubsection{What is DSR}

According to Venable and Baskerville (2012, p.142), DSR can be defined as research that "invents a new purposeful artefact to address a generalized type of problem and evaluates its utility for solving problems of that type". Artefacts in this context refer to artificially made objects and their processes as defined by Goldkuhl (2002). Venable and Baskerville (2012) elaborated on four key components of their definition:

- Purposeful artefact: A purposeful artefact is one that is designed to achieve a specific human goal or objective. This artefact could be a technology, a procedure, a technique, a methodology or a combination of any of these.

There are two forms of purposeful artefacts, namely:

1 product artefacts, which could be real (e.g., an instantiation of a decision support system) or abstract (e.g., models and methods)

2 process artefacts (e.g., methods) (Goldkuhl, 2002; Gregor and Jones, 2007).

A purposeful artefact could include both a product and its associated process. For example, a framework artefact could comprise of both the framework itself (product) as well as a method for its application. 
- An invention: This involves some form of creation, design, improvement or adaptation. The invention does not have to be built from scratch.

- Address a generalised problem type: The resulting artefact and the process to create it, is such that it can be repeatedly applied to solve different occurrences of the problem type, not just a specific problem.

- Evaluation: Evaluation of the resulting artefact provides assurance that it is capable of solving the problem type for which purpose it was created. This attests to the usefulness of the artefact.

Over time, many authors have published articles focusing on different aspects of DSR. These include DSR processes/approaches (e.g., March and Smith, 1995; Peffers et al., 2008; Vaishnavi and Kuechler, 2015, etc.), guidelines for the use of DSR (e.g., Kotzé et al., 2015; Hevner et al., 2004, etc.), DSR outputs or artefacts (e.g., Kotzé et al., 2015; Vaishnavi and Kuechler, 2015; Hevner et al., 2004; March and Smith, 1995, etc.), evaluation methods for DSR artefacts (e.g., Hevner et al., 2004; March and Smith, 1995, etc.), review of different forms of artefacts emanating from a selection of DSR studies (e.g., Amrollahi et al., 2014; Ayanso et al., 2011; Bucher and Winter, 2008), and ethical principles that guide the conduct of DSR (e.g., Myers and Venable, 2014).

The scope of this paper is limited to DSR outputs/artefacts, and specifically the process followed in the development of a method artefact. The remaining two subsections therefore provide an overview of DSR artefacts (Section 2.2.2) and an overview of a generic DSR methodology (Section 2.2.3).

\subsubsection{DSR artefacts}

An artefact type created/produced during a DSR process in the field of IS can take the form of constructs, models, methods, frameworks, instantiations or better theories (Hevner and Chatterjee, 2010; Hevner et al., 2004; Kotzé et al., 2015; March and Smith, 1995; Vaishnavi and Kuechler, 2015; Verbrugge, 2016).

Constructs consist of the vocabularies used to describe a given problem or solution. Constructs could also represent the language and knowledge that are shared by a group of researchers in a discipline (Hevner et al., 2004; March and Smith, 1995). A model is the set of propositions or statements that describe the relationships between constructs. Models emerge when a research problem is conceptualised, and they are typically refined throughout the DSR process. Models could also be the abstraction or a simplified representation of a given problem or solution (Hevner et al., 2004; March and Smith, 1995).

A method is the set of steps, process or systematic approach to execute a given task. Methods provide a cohesive and consistent way of performing a task to achieve the desired result (Hevner et al., 2004; March and Smith, 1995; Purao, 2002; Vaishnavi and Kuechler, 2015). Another way of looking at a method is the plan of action to achieve an objective. A framework provides generic structure that could be used to achieve a specific objective. A framework can also include a model and the associated method to use or implement the model (Kotzé et al., 2015; Verbrugge, 2016).

An instantiation is the actualisation of a specific construct, model, method or framework. Instantiations provide the means of demonstrating the feasibility and 
effectiveness of constructs, models or methods in a given environment (Hevner et al., 2004; March and Smith, 1995).

Better theories are artefact constructs similar to the experiments in natural sciences (Purao, 2002; Vaishnavi and Kuechler, 2015). The reasoning process of reflection and abstraction facilitates knowledge contributions that may result in better theories (Vaishnavi and Kuechler, 2015).

In this paper, the focus is primarily on the creation/design of a method artefact.

\subsubsection{Overview of a generic DSR methodology}

Several DSR methodologies or process models have been proposed over time. Examples include the methodologies put forward by Hevner et al. (2004), Purao (2002), March and Smith (1995), Gregg et al. (2001) and Peffers et al. (2008). In this section, we describe the generic DSR methodology that was used as the main guiding approach in the development of SMeHI, namely the DSR process model proposed by Vaishnavi and Kuechler (2015), as illustrated in Figure 1.

Figure 1 DSR process model proposed by Vaishnavi and Kuechler (2015)

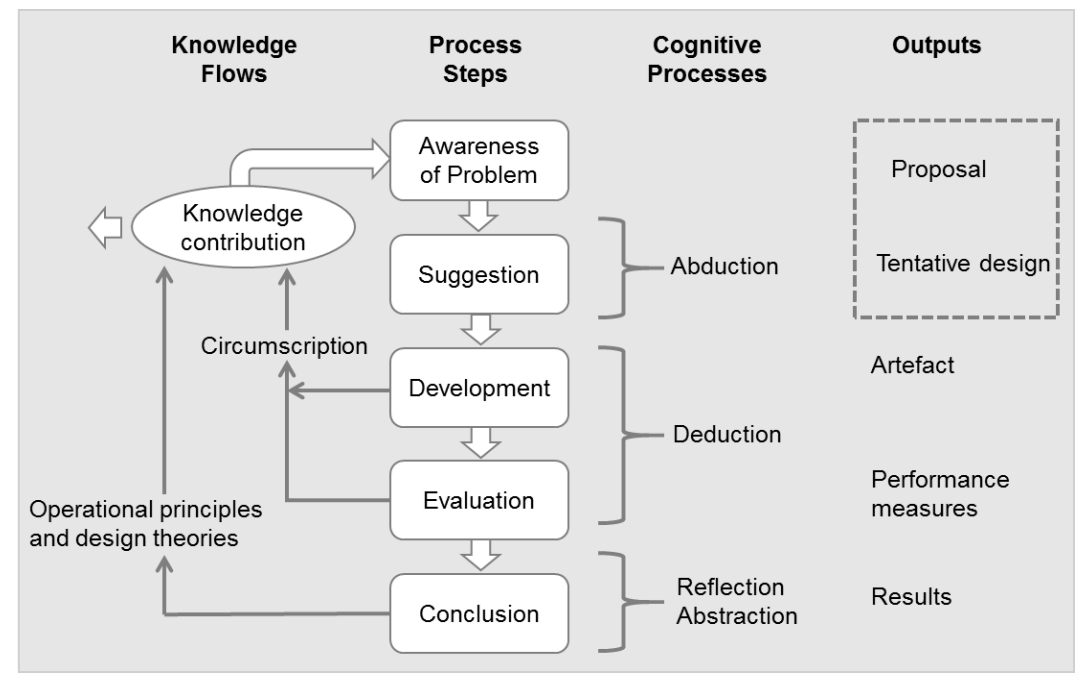

The process consists of five iterative phases, namely:

- Awareness of problem: In this phase a research problem is defined or refined (in further iterations/cycles). Problem awareness can originate from several sources, including new developments in industry or academia.

- Suggestion: This phase is closely linked to the awareness phase. It is a creative process where the researcher envisions new functionalities. The new functionalities may be based on new or existing components of an artefact. The output of this phase can, for example, be an envisaged solution, a proposal for a prototype, design guidelines, etc. 
- Development: In this phase the solution to the problem is designed and the artefact created. This can be a partial solution, requiring further iterations, or a complete solution.

- Evaluation: This is the phase where the artefact is assessed against the specified evaluation or design criteria. Quantitative and qualitative methods could be used to explain deviations from the expected behaviour of the artefact. Inherent in the evaluation phase is an analytic sub-phase, where a researcher makes hypotheses about the behaviour of the artefact. The evaluation results and lessons learnt from the development phase are fed back to the next iteration of the design process. Various evaluation methods that can be used are presented in more detail in Section 2.2.4.

- Conclusion: The conclusion phase marks the end of a research cycle and ends with the development of a satisficing, though not necessarily optimal, artefact. The researcher also reflects on the research process to determine the lessons that can be learnt in order to contribute to the body of knowledge. The outcome of the research is also communicated to the relevant audience.

Inherent in the DSR process model is the action of circumscription (Vaishnavi and Kuechler, 2015). Circumscription happens when the results of the evaluation, or additional information gained during the development of the artefact is brought together and fed back to another iteration of awareness and/or suggestion. This action enables the researcher to iterate through the problem awareness, suggestion, development and evaluation phases, facilitating knowledge and understanding that could only be gained through the act of artefact construction.

The process of circumscription also supports contribution to the body of knowledge, typically comprising operational principles and design theories (Vaishnavi and Kuechler, 2015). An operational principle is defined as "any technique or frame of reference about a class of artefacts or its characteristics that facilitates creation, manipulation and modification of artefactual forms" [Purao, (2002), p.6], i.e., specifying ways of doing things in a reproducible manner.

Operational principles, as defined, relates directly to method artefacts as knowledge contribution. Knowledge contribution in DSR is discussed in more detail in Section 2.2.5.

\subsubsection{Evaluation methods for DSR artefacts}

Evaluation of the ensuing artefact is an integral part of any DSR process. Evaluation allows researchers to justify the utility, quality and efficacy of an artefact (Hevner et al., 2004).

Hevner et al. (2004) identify a number of approaches that could be used to evaluate a DSR artefact. The observational approach can take the form of a case study, where an indepth study of the artefact is undertaken in an appropriate environment. It can also involve field studies where the use of the artefact is monitored in several environments. Analytical evaluation can take one of four methods, namely:

1 static analysis, where the structure of the artefact is examined for the presence of pre-defined qualities

2 architecture analysis, where the extent to which the artefact fits into a given technical IS architecture is evaluated 
3 optimisation analysis, where the fundamental optimal features of the artefact are demonstrated

4 dynamic analysis, which involves an assessment of the dynamic qualities of the artefact.

An experimental evaluation can be in the form of a controlled experiment, where the artefact is assessed in a controlled environment like a laboratory, or by simulating the operation of the artefact using artificial data. Testing can take the form of functional testing, where the interfaces of the artefact are tested for any defect, or structural testing, where some paths of the artefact are selected to evaluate their level of coverage. Descriptive evaluation can be done through informed arguments, where existing knowledge are used to construct a convincing argument on the utility of the artefact or through the development of scenarios around the artefact to demonstrate its utility.

The method used to evaluate the SMeHI artefact is descriptive and observational. It involved the use of hypothetical scenarios and real-world application.

\subsubsection{Knowledge contribution in DSR}

Knowledge contribution in DSR could fall into one of three main categories, including conceptual, descriptive or prescriptive knowledge. Conceptual knowledge refers to concepts, classifications, taxonomies, conceptual frameworks, typologies, etc. (Gaß et al., 2012; Iivari, 2007). Descriptive knowledge relates to the 'what' knowledge about natural phenomena, as well as the laws that guide them. This includes observational facts, empirical regularities, theories, hypotheses, etc. (Gaß et al., 2012; Gregor and Hevner, 2013; Iivari, 2007; van Aken, 2005). Prescriptive knowledge represents the 'how' knowledge of man-made artefacts and includes design process knowledge, design product knowledge, methods, etc. Prescriptive knowledge is aimed at providing solutions to specific problems (Gaß et al., 2012; Gregor and Hevner, 2013; Iivari, 2007; van Aken, 2005).

In their $2 \times 2$ matrix framework, Gregor and Hevner (2013) described how DSR can contribute to existing knowledge. The framework, as illustrated in Figure 2, is based on the level of problem space maturity and the solution maturity.

Contributions in the improvement quadrant provide new or better solutions to known problems. Such improvement could be in the form of increased efficiency, improved quality or increased productivity. DSR contributions that fall in the improvement quadrant are generally in the prescriptive knowledge base. However, further evaluation of the artefact emanating from the research process could lead to better understanding of existing theories, thereby contributing to descriptive knowledge base.

Contributions in the invention quadrant represent new research in areas where there is little or no knowledge of the problem space and new solutions are proffered. However, inventions in true sense of the word are very rear. New knowledge can be contributed to the descriptive and/or prescriptive knowledge base.

In exaptation, known solutions are adapted or extended to solve new problems. This can occur when artefacts that have been effectively used to resolve similar problems in another discipline is applied to answer current research questions. Exaptation research contributes to the prescriptive knowledge base, but descriptive knowledge contributions may also emerge from better understanding of the new artefacts during their use. 
Generally, routine design (the application of known solutions to known problems) rarely involves the use of research methods to solve the problem at hand. However, routine research could lead to surprises or unexpected discoveries. Such discovery could then change the research contributions to one of the other quadrants.

Figure 2 Framework for DSR knowledge contribution

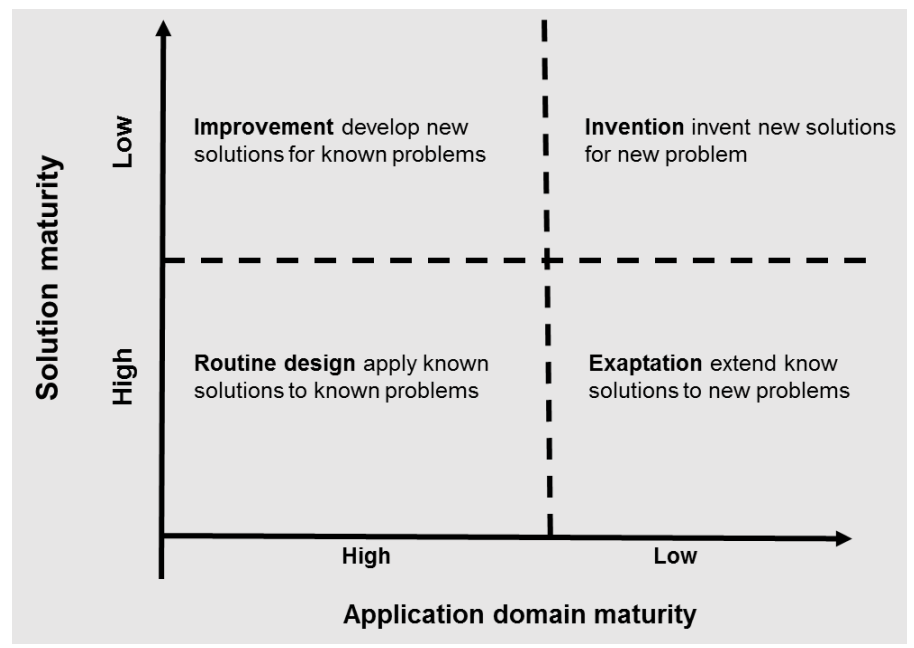

Source: Adapted from Gregor and Hevner (2013)

In agreement with IS researchers, e.g., Gregor and Hevner (2013), Gaß et al. (2012), Iivari (2007) and researchers in fields such as management sciences, e.g., van Aken (2005), the knowledge contribution of the research related to SMeHI is of the prescriptive type. SMeHI is a method on how to select the set of standards to enable interoperability between HISs. It also maps to the improvement quadrant of the Gregor and Hevner (2013) knowledge contribution framework.

\subsection{Overview of previous studies on method development}

Despite an apparent increase in the number of publications on DSR method artefacts, we noted paucity of publications with details of the process followed to create method artefacts, in and of itself. However, some examples do exist. This section provides an overview of two such previous studies on method development that relates to the domains covered by SMeHI. Section 2.3.1 is a review of method development using DSR in the knowledge discovery domain. The study used DSR to create a method artefact and is similar to the process followed to create SMeHI. Section 2.3.2 gives an overview of the development of a method for assessing information and communication technology (ICT) interoperability standards and specifications. This study involved a method for assessing the suitability of ICT standards to support interoperability, just as SMeHI is aimed at selecting the standards that support interoperability between HISs. Section 2.3.3 reflects on the usefulness/suitability of these two methods for the purposes of developing a method to guide the selection of e-health standards to support interoperability among healthcare systems/applications in the African context, taking into account the target 
audience, i.e., government agencies in Africa responsible for making recommendations on e-health standards to adopt at local, regional or national level.

\subsubsection{Example of the use of DSR to create a method artefact}

One publication with a detailed description of the process that created a method artefact is "A method to integrate knowledge discovery techniques with prior domain knowledge for better decision support", by Kunene and Weistroffer (2006). The research was based on a single cycle of the Vaishnavi and Kuechler (2015) DSR process model.

In the awareness of problem phase of the DSR process, the authors motivated the need for the proposed method by articulating gaps in previous work on knowledge discovery in databases (KDD) and the absence of a generic method/process to integrate domain knowledge with available knowledge discovery techniques. Another justification for the proposed method was the need to develop tools that support modelling in the problem definition phase of KDD process as identified in previous related studies. The suggestion phase looked at conventional approach to knowledge discovery, and then presented an overview of the proposed method and how it differed from conventional methods.

In the development phase, the authors focused on the process followed to create the artefact. This included a series of interviews with domain experts, conceptualisation, development and refinement of the domain decision structure model. The development phase also included a brief overview of the method (artefact) that came out of the research. To illustrate the utility of the designed artefact, the authors in the evaluation phase applied the method to a number of knowledge discovery process instantiations. The results of the evaluation were compared with outcomes from the traditional method. Domain experts also validated the efficacy of the method.

There was no explicit conclusion or contribution phase to the DSR process in the paper, although publication of the research could qualify as a valid activity in the conclusion phase of the Vaishnavi and Kuechler (2015) DSR process model.

\subsubsection{Overview of the common assessment method standards and specification}

The common assessment method standards and specification (CAMSS) was a European Union (EU) initiative. The objectives of the initiative were to:

1 provide European administrations with a well-defined, easy-to-use framework and method for assessing ICT interoperability standards and specifications

2 facilitate easier and faster assessment of ICT standards and specifications

3 maximise the benefits of ICT through appropriate use of standards in ICT procurements

4 address challenges associated with long-term contracts and vendor lock-in, which made it difficult to take advantage of new technologies

5 facilitate collaboration and knowledge sharing between member states in the evaluation of interoperability standards for ICTs to support e-government.

CAMSS was developed iteratively in two phases. A series of assessment quality criteria were defined during the first phase of the CAMSS method development. The criteria 
drew heavily on member states' best practices and were agreed to by experts. Public consultations and information presentations on CAMSS were also held (European Commission, 2012b). The second phase of the CAMSS method development focused on a pilot assessment using the outputs of the first phase. Further refinements were made to the assessment criteria in the second phase, and the CAMSS method, i.e., the artefact itself, was developed. To define the CAMSS method, an analysis of the prevailing situation in member states was performed. Three sets of assessment scenarios were defined, and common steps in the scenarios were identified, selected and described (European Commission, 2012b).

The final CAMSS method has six process steps (European Commission, 2012a):

- Proposal: In this step, a new proposal for an interoperability specification is registered. This could take the form of a proposal to meet specific business needs.

- Consideration: Here, a panel of experts evaluate the proposal and select (using a set of pre-defined criteria) the relevant standards specifications that could meet the business needs.

- Assessment: In this step, the panel of experts evaluate the standards specifications to determine their suitability to the business needs. Relevant stakeholders, e.g., public administrators, standardisation organisations, etc., could be consulted to validate the results of the assessment.

- Recommendation: Based on the results of the assessment, a recommendation is made on whether the standards should be adopted or rejected.

- Authorisation: This step involves a final decision by those with relevant authority on the adoption of the standards specification.

- Adoption: This step takes the form of formal execution of the authorisation to adopt the standards specification.

The CAMSS method can be used by different categories of role players (standards setters, senior managers, strategist, business case authors, procurement practitioner and technical architects) (European Commission, 2012a).

\subsubsection{Usefulness of the methods for our objectives}

Having reviewed the processes to create the method for knowledge discovery (Kunene and Weistroffer, 2006) and the CAMSS method (European Commission, 2014, 2015), a logical question is whether any or both of these methods meet the need for guidance on the selection of e-health standards to support the interoperability of healthcare systems in Africa. The main users of such as method would be African Government agencies with the responsibility to decide on the set of standards to be adopted at local, regional or national level. We are of the view that the answer is 'no', for a number of reasons:

- The multidisciplinary nature of the healthcare environment makes it much more complex than the process of knowledge discovery in single elementary domains. This is partly due to the complex composition of the human body that do not accord itself to a single field of expertise (Ryan, 2006) and the many individual differences that may exist. 
- Achieving interoperability in the healthcare environment is also much more difficult than the interoperability requirements between general-purpose IT systems. This is especially the case at semantic interoperability level. There is always a potential for ambiguity in the use of medical terms, which requires a shared and equally understood vocabulary between healthcare systems (Benson, 2010; Gibbons et al., 2007).

- The CAMSS method is useful where users have the technical expertise to evaluate the standards under consideration. This kind of expertise is generally not available in many African countries.

After considering the shortcomings described above we can justify the need for developing a method artefact capable of addressing the limitations. To fill this gap, the generic SMeHI method was developed to guide African countries in the selection of the e-health standards to specifically support the interoperability of healthcare systems on a national level. Section 3 describes the process to develop the SMeHI method artefact.

\section{DSR process to design the SMeHI 0 HMRG}

The process to develop the SMeHI artefact was guided by the DSR process model proposed by Vaishnavi and Kuechler (2015). The process, as illustrated in Figure 3, involved one primary DSR cycle of problem awareness, suggestion, development, evaluation and conclusion phases. The development phase of the primary DSR cycle consisted of four DSR sub-cycles, each with a problem awareness, suggestion and development phases.

The remainder of this section describes each of the cycles in more detail. In Section 3.1, we present the problem awareness and suggestion of the primary DSR process. Section 3.2 contains the development phase and five sub-phases of the DSR process. Section 3.3 and Section 3.4 present the evaluation and conclusion phases, respectively.

\subsection{Problem awareness and suggestion phase of the primary DSR process of the development of the SMeHI method}

As stated in Section 2.1, the level of e-health standards adoption at national level is low in many African countries. Furthermore, there is currently no generic process to determine the set of e-health standards that should be adopted to support interoperability. Although many developed countries have adopted e-health standards at national level, the approaches followed by these countries are often not publicly available. The few countries that made their methods partially available (see Section 3.2.4) followed different, often not compatible, approaches to determine their choice of e-health standards. For example, Ireland followed a consultative approach to arrive at the set of standards adopted by the country (HIQA, 2011). Kenya on the other hand based their choice on the specified functional requirements for the country's EMR systems (Ministry of Medical Services and Ministry of Public Health and Sanitation, 2010). The problem with the use of different approaches is inconsistency and lack of replication. 
Figure 3 SMeHI DSR development phases (see online version for colours)

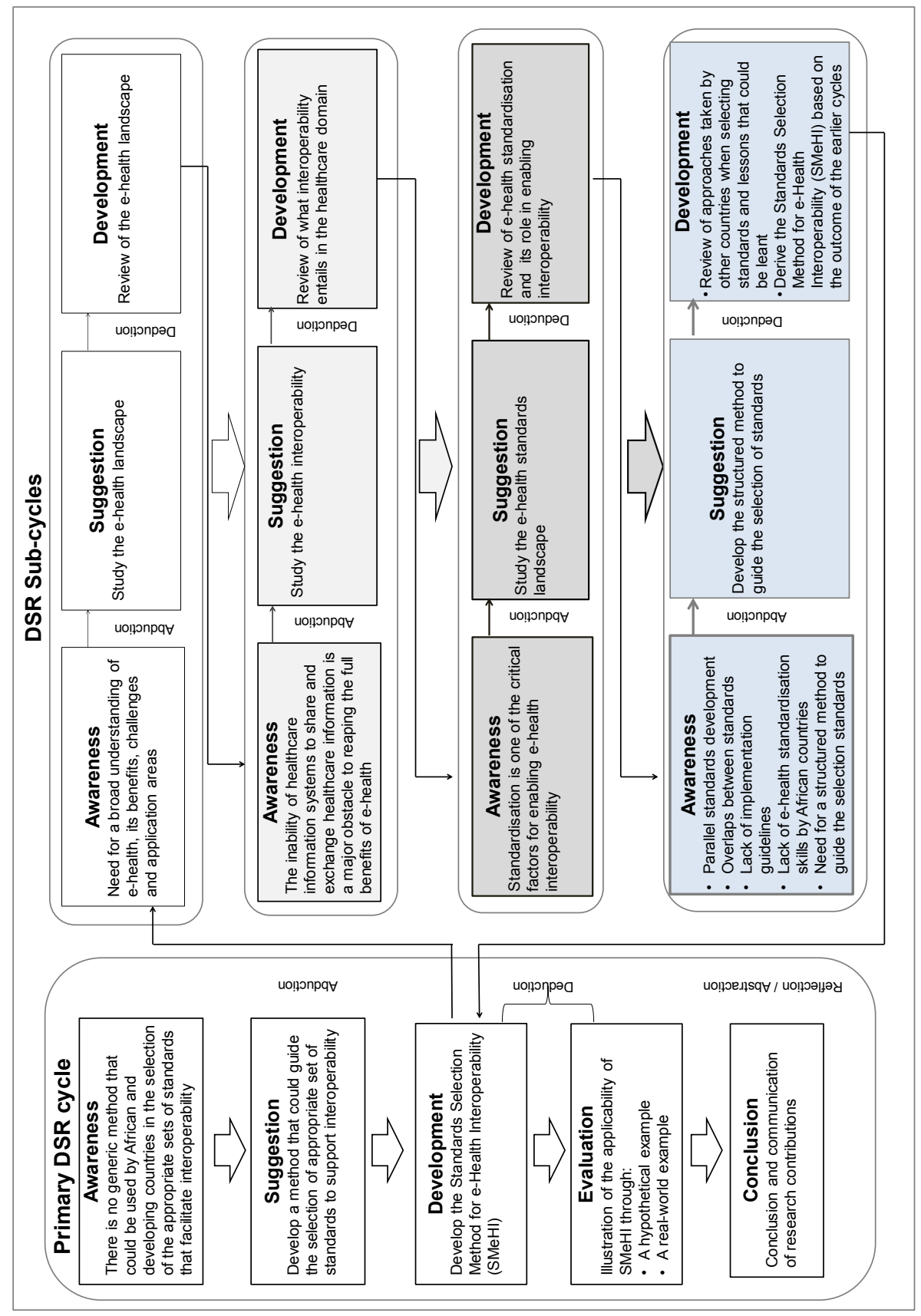


In response to the WHO (2014) call for guidance to LMICs on how to decide on standards to adopt, we identified the need for a generic structured method to guide such a decision. The high level of skills shortage in many developing and African countries, also in the e-health standardisation domain, is well documented (The Rockefeller Foundation, 2010).

With the special need of African countries in mind, the suggestion was to develop the generic SMeHI method to guide the selection of the e-health standards to support the interoperability of healthcare systems specifically. As alluded to by van Aken (2004), knowledge from any given DSR effort is intended for professionals in that field. The intended users of SMeHI are government agencies in Africa responsible for making recommendations on e-health standards to adopt for implementation at local, regional or national level, as well as those agencies responsible for the development of country-specific standards. Such users should of necessity have the requisite technical skills to make standards selection recommendations.

The design objectives identified for SMeHI were:

- $\quad$ SMeHI should provide a phased approach to the selection of e-health interoperability standards.

- $\quad$ SMeHI should provide applicable implementation guidelines that support interoperability.

- $\quad \mathrm{SMeHI}$ should provide guidance on where to find information on standards to consider.

- Someone not skilled in the finer detail of e-health interoperability standards should be able to follow SMeHI with ease.

\subsection{Development phase of the SMeHI method}

The development phase of SMeHI consisted of four sub-cycles (determining the e-health landscape, study interoperability in the context of e-health, study standardisation as a driver of e-health interoperability and an overview of current approaches to e-health standards selection). Each sub-cycle consisted of problem awareness, suggestion and development, as discussed in the following sub-sections.

\subsubsection{Sub-cycle 1: determining the e-health landscape}

The problem awareness for this sub-cycle was that there is a need to understand e-health, its potential benefits and challenges to its adoption. To address this need, the suggestion was to study the e-health landscape to form deeper understanding of what it entails.

The development phase involved a review of literature on e-health landscape. Here, we studied existing literature on e-health, benefits and challenges to their adoption, and the application areas of e-health. The main issue that emerged from this sub-cycle was that fragmentation of healthcare systems made it difficult to reap maximum benefits from e-health.

This led to another problem awareness phase, which kick-started sub-cycle 2 that looked at what interoperability entails in the e-health context. 


\subsubsection{Sub-cycle 2: interoperability in the context of e-health}

The main problem awareness for this phase is the fact that inability of healthcare systems to share information continue to hamstring the potential benefits of e-health solutions. Hence, there is a need to understand what interoperability entails in the healthcare environment. The suggestion was to study what e-health interoperability entails.

The development phase involved review of literature on e-health interoperability, its benefits and associated complexities. We also looked at the four main levels of interoperability, namely technical, syntactic, semantic and organisational interoperability (Adebesin et al., 2013).

We found that interoperable healthcare systems facilitate timely access to patient information and improved patients' safety. Healthcare professionals are also empowered to make informed decisions about the appropriate care for their patients (Kun, 2007; Walker et al., 2005). We also found that attaining e-health interoperability is more difficult when compared to other sectors like banking and finance. This is partly due to complexity of the human body, which does not lend itself to a complete understanding by a single person and the many individual differences that may exist.

In an earlier publication (Adebesin et al., 2013), we applied the World Health Organization and International Telecommunication Union (WHO and ITU, 2012) e-health components to illustrate the factors that are essential to effectively drive interoperable e-health initiatives. One of the identified drivers was standardisation. In order to deal with the fragmentation of healthcare systems, the use of standard-compliant systems is necessary.

This led to another problem awareness phase to study the role of standardisation in e-health that kick-started sub-cycle 3 .

\subsubsection{Sub-cycle 3: standardisation as a driver of e-health interoperability}

The vital role of standardisation in enabling e-health interoperability was evident from outcome of sub-cycle 2. Hence, the problem awareness phase related to the need to understand this vital role in more detail. To address the need, the suggestion was to study the e-health standards landscape in detail.

The development phase involved a review of typical e-health standards in use by African countries, other published e-health interoperability standards and organisations involved in their development. The study found that due to inadequate skills in many African and developing countries, the majority of African countries have not moved beyond the basic disease classification standard, ICD-10 (WHO, 2016a). The study also showed that hundreds of other possibly applicable standards in the e-health domain have been published internationally. Furthermore, we found that it is usually impossible for a single standard to cover all of any real-world requirement in the health domain. As such, it is necessary to combine several standards, which could in turn potentially jeopardise interoperability (CEN et al., 2009). To compound the problem standards are often not accompanied by implementation guidelines.

Thus, we decided to investigate the approaches followed by other countries to determine the standards to adopt. This resulted in a new problem awareness phase that kick-started sub-cycle 4. 


\subsubsection{Sub-cycle 4: current approaches to the selection of e-health standards to support interoperability}

The problem awareness phase for this sub-cycle was a need to determine approaches currently used by countries that have adopted e-health standards. The suggestion was therefore to study publicly available information on the processes followed by countries that have adopted e-health standards at national level.

In contrast to the first three sub-cycles, the outcome of this sub-cycle is presented in more detail. The reason for this is that the approaches followed by the various countries would directly relate to the concept of method artefacts, similar to the aim of this paper.

An overview is provided of a selection of representative e-health standards selection approaches by presenting the Canadian, the European Commission, Ireland and Kenyan approaches in the sub-sections that follow.

\subsubsection{The Canadian e-health standards adoption approach}

Canada's standards selection process consists of four phases (Canada Health Infoway, 2012):

- Needs identification and business definition: The businesses, clinical and technical requirements to be supported are defined.

- Options research and analysis: Potential standards that could meet the requirements are identified. Criteria, gap and cost analyses, and risk assessments are done to determine the viability of the standards.

- Specification development: Depending on the outcome of the phase above, pan-Canadian implementation guidelines could be developed for existing standards or new standards could be created.

- Maintenance: This provides a structured mechanism for maintenance of standards. Lessons from the implementation of standards are documented in this phase.

The resulting standards from this process were Health Level Seven Version 3 (HL7, 2017), the Clinical document architecture (CDA) (HL7, 2013a), the Digital Imaging and Communication in Medicine (NEMA, 2017), the pan-Canadian LOINC Observation Code database (pCLOCD) (Canada Health Infoway, 2017), the systematised nomenclature of medicine clinical terms (SMOMED-CT) (SNOMED International, 2017), ICD-10-CA (CIHI, 2017), and Integrating the Healthcare Enterprise (IHE) CrossEnterprise Sharing for Imaging (XDS-I) profile (IHE, 2016b).

\subsubsection{The European Commission e-health standards adoption approach}

Increase in cross-country mobility of patients and healthcare professionals in Europe and the growth in the number of aged citizens, resulted in calls for sharable healthcare information across Europe (Thorp, 2010). To address this need the European Commission in 2007 issued a mandate (M/403) (European Commission, 2007) to coordinate the adoption of e-health standards across Europe. In response to $\mathrm{M} / 403$ the eHealth-INTEROP Report proposed five broad processes to address e-health interoperability and standardisation requirements for EU member states (CEN et al., 2009), namely: 
- Use case definition and prioritisation: In this phase, business use cases are proposed by member states. The proposals are then analysed to prioritise them.

- Standards development: This phase entails harmonisation of existing standards to address current and future overlaps between the standards.

- Profile development and maintenance: This phase involves the decomposition of business use cases into technical use cases. Relevant standards for a given technical use case are combined and constrained, i.e., profiled.

- Profile quality assurance test plans and tools: This phase involves the coordination of conformance test plans and tools for use case profiles.

- Sharing of best practices in deploying e-health projects: This phase provides a platform for exchange of experiences and the publication of best-practice guidelines for deployment of e-health projects across Europe.

The European Commission standardisation process was implemented through European-wide e-health projects. One example of the implementation is the Antilope (2014) project, where use cases were developed around the exchange of patient summary, requesting and sharing of laboratory/radiology results, electronic prescription and dispensing, etc.

\subsubsection{Ireland e-health standards adoption approach}

Ireland's standards adoption process involved wide consultations with key stakeholders (suppliers, purchasers and implementers of HISs, healthcare professionals, etc.). This process identified a need for standards in the categories of patient, provider and healthcare institution identification, clinical terminology, and messaging (HIQA, 2011). Existing standards and international experiences on standards adoption were studied and several candidate standards identified. These include HL7 Version 2.X (HL7, 2013b), HL7 Version 3 messaging standard (HL7, 2017), and HL7 CDA (HL7, 2013a). Each candidate standard was analysed, using a tool comprising five principles and assessment criteria. The principles and sample criteria (in brackets) were:

1 standards must be clinically relevant (clinical appropriateness, clinical outcome, etc.)

2 standards must meet specific business needs, (business need, maturity/stability, etc.)

3 standards must be vendor neutral and backward compatible (vendor neutral and backward compatibility)

4 standards must be financially viable (affordability and implementation costs)

5 standards must have established governance and processes (intellectual property, governance structure, etc.) (HIQA, 2012).

Following their assessment, Ireland endorsed HL7 Version

2.X (2013b), HL7 CDA (2013a), LOINC (Regensief Institute, 2017), the International Classification of Primary Care, second edition (ICPC-2) (WHO, 2003) and ICD-10 Australian Modification (ICD-10-AM) (Australian Consortium for Classification Development, 2017) for national adoption (HIQA, 2012, 2013). 


\subsubsection{Kenyan e-health standards adoption approach}

Kenya's approach to select e-health standards to be adopted was based on the country's guideline for EMR systems (Ministry of Medical Services and Ministry of Public Health and Sanitation, 2010). The guideline document specifies six key functional areas that must be supported by any EMR system implemented in the country. These are:

1 basic demographic and clinical health information

2 clinical decision support

3 order entry and prescribing

4 health information and reporting

5 security and confidentiality

6 exchange of electronic information.

Based on the six functional requirements, Kenya decided to adopt the HL7 (2013b) messaging standard to support the exchange of healthcare information, and the Statistical Data and Metadata Exchange (SDMX-HD) (Global Inventory of Statistical Standards, 2010) to support the transmission of health indicators to the district health information system (DHIS). HL7 CDA (2013a) was also selected to enable the exchange of clinical documents like medical summaries. Thus, the guideline for EMR systems and the associated standards is aimed at ensuring that EMR system developers implement interoperable systems. It should be noted that there was no indication of the factors that influenced the selection of these standards, or why other standards that could provide the same kind of support, were not selected.

\subsubsection{Developing SMeHI}

\subsubsection{Lessons from the review of standards adoption approaches}

The development of SMeHI drew heavily on the lessons learnt from the approaches followed by the countries reviewed in sub-cycle 4 .

One of the key lessons we learnt from the review of countries' approaches to the selection of e-health standards to support interoperability is that different types of approaches were followed by the countries reviewed to arrive at the set of e-health standards. We also found that the adoption of e-health standards should be aligned with the interoperability needs of a country. The first phase of standards determination for Canada and Ireland, and implicitly, in the European Commission approach, involved identification of the needs that would be addressed by standards adoption. In the case of the European Commission, this was done through the development of use cases.

We also noted that in all cases where the use of e-health standards to support interoperability was introduced with reasonable success, the countries had a high level, national entity that directed the standards adoption process. This is to ensure better coordination and alignment with national priorities, as advised by the WHO and ITU (2012) in the National eHealth strategy toolkit document.

It was also found that the process of deciding on the set of standards to adopt, especially at national level, should involve all relevant stakeholders. This will ensure 
active participation and limit the probability of resistance to changes from the 'usual way of doing things' when the use of standards is introduced.

In addition, we found that because of the consensus-based process of standards specifications by international standards development organisations (SDOs), standards may not necessarily address unique needs of a specific country. As such, the adoption of e-health standards will most likely require localisation to adapt them to a country's unique needs. This kind of localisation requires a deep understanding of the standard and the standards landscape. The absence of necessary standardisation skills and expertise by many African and developing countries make the adoption and localisation of e-health standards much more difficult.

In Section 3.2.5.2, we present SMeHI and discuss the factors that influenced each phase of the development of the method.

\subsubsection{Overview of the SMeHI method}

Using deductive reasoning and circumscription, best practices and lessons learnt during sub-cycles 1 to 4 were combined to form the proposed SMeHI, as illustrated in Figure 4.

Figure 4 The SMeHI method (see online version for colours)

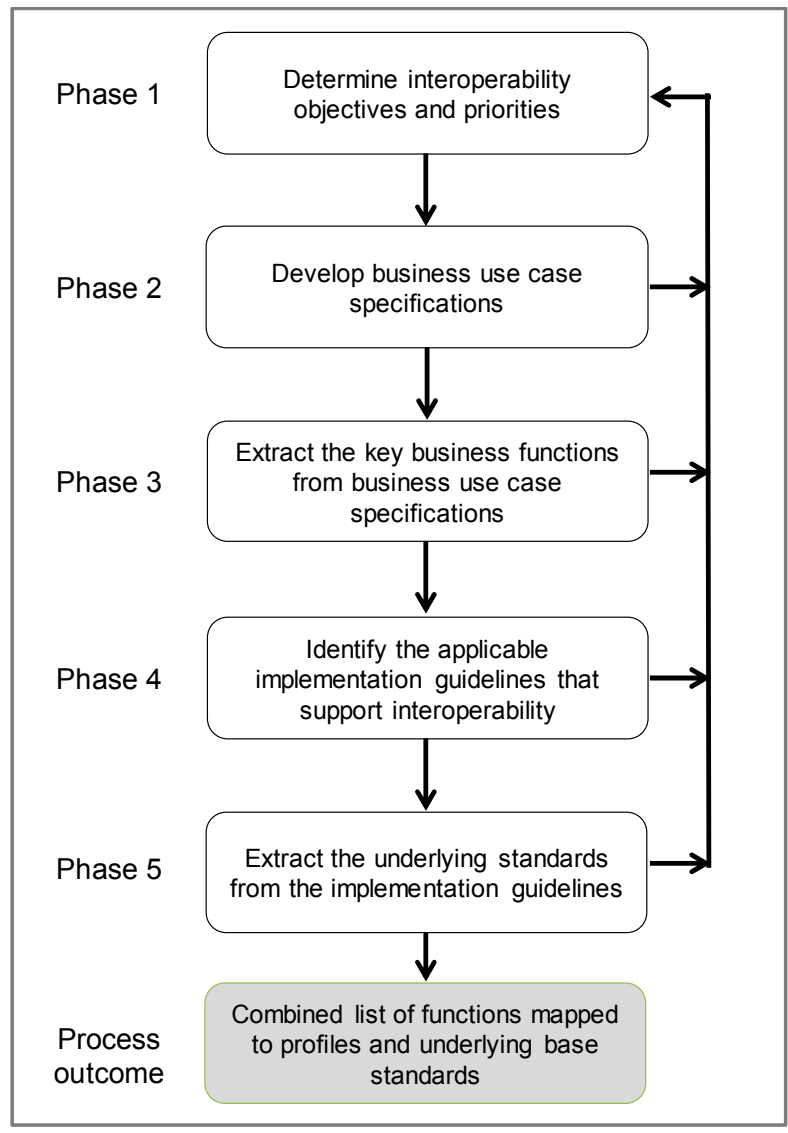


SMeHI consists of five phases, namely:

- Phase 1-Determine interoperability objectives and priorities: kick-starting the standards selection process, this phase articulates the interoperability needs/objectives that should be supported by the adoption of e-health standards explicitly. As indicated in Section 3.2.5.1, a common theme in the approaches followed by countries, with the exception of Kenya, was to identify and specify the requirements that should be addressed by any given standard adopted.

Based of lessons learnt during sub-cycles 1 to 4 and countries best practices, we deduced that interoperability objectives should be driven by health priorities so that limited resources are directed at areas of greatest need. This is particularly the case with African countries where several projects often compete for limited resources. Relevant stakeholders should be involved in this process to ensure that valuable inputs are received and continued support is provided throughout the process (WHO and ITU, 2012).

As such, SMeHI begins with determination of interoperability objectives that would guide the selection of standards to adopt. Setting up objectives upfront enables users of SMeHI to articulate the 'what do we want to achieve' question. Because the adoption of e-health standards would impact on work processes of different people, this process should involve all relevant key stakeholders to get their buy-in.

- Phase 2-Develop business use case specifications: similar to the European Commission approach, SMeHI makes use of use case scenarios to document healthcare processes. A scenario describes user interactions with a system to achieve specific goals. These scenarios facilitate the identification of specific processes where the exchange of health information is crucial for their execution. This approach is beneficial in that it allows healthcare professionals, who may not necessarily be versed in technical terminologies to describe their work processes in the 'language' they are comfortable with (McCormick, 2011).

In SMeHI, business use cases are therefore used to describe healthcare processes to enable the identification of work processes that require information exchange for their implementation. This approach provides a technology-independent way of specifying interoperability requirements. The development of business use cases should involve as many relevant stakeholders as possible, e.g., healthcare professionals/clinicians, e-health standards experts, policy makers, etc. Because $\mathrm{SMeHI}$ is specifically aimed at enabling interoperability on a national level, these business use cases should be driven by national health priorities.

- Phase 3-Extract the key business functions from business use case specifications: business functions are the series of actions involving one or more entities to achieve specific organisational objectives (Modell, 2007). These can be identified as phrases with action verbs (e.g., order laboratory tests) in business use cases (Department of Defence Systems Management College, 2001). Business functions could be explicitly stated or derived from requirement specifications. SMeHI allows business functions to be derived from the use cases developed in phase 2 . The business functions would in turn guide the determination of the standards required to support the exchange of healthcare information. 
- $\quad$ Phase 4 - Identify the applicable implementation guidelines that support interoperability: as discussed in Section 3.2.3 interoperability can be achieved by combining several standards, which could potentially mean combining incompatible or conflicting standards.

SMeHI also had to take into account the skills shortage in many African countries in the e-health and standardisation domains. The nature of e-health standards is such that it is almost always necessary to combine several standards to meet real-world interoperability needs. This could potentially jeopardise the very interoperability that is being sought. As such, SMeHI should not require its users to make decisions on which individual standards to combine. SMeHI consequently recommends interoperable stacks of standards to be considered.

Based on our review of published e-health standards, we found that the risk of conflicts between standards could be mitigated by

1 adopting the HL7 Version 3 product suite (HL7, 2017)

2 using the suite of ISO 13606 electronic health record standards 1-5 (ISO, 2008a, 2008b, 2009a, 2009b, 2010)

3 using the standards-based IHE (2016d) profiles.

The choice between which of these three stacks of standards to use would be influenced by available skills and expertise in a particular situation/country.

Because SMeHI is specifically targeted at African countries, it leans more towards the use of IHE profiles. These profiles give detailed descriptions of how standards should be used and combined to address specific clinical requirements. It also comes with a comprehensive set of guidelines to support various use cases towards interoperability. Other countries with sufficient expertise in the use of HL7 Version 3 (HL7, 2017) product suite or ISO 13606 (ISO, 2008a, 2008b, 2009a, 2009b, 2010) standards may alternatively consider either of these two standard suites.

- Phase 5 - Extract the underlying standards from the implementation guidelines: IHE profiles contain specific standards required to address a given interoperability requirement. Users of SMeHI do not have to decide on which combination of standards to use. What is required in this phase is to get the list of standards specified in the applicable profiles to arrive at the set of standards to adopt. Because IHE profiles are tried and tested, the risk of conflicts between incompatible standards are reduced (IHE, 2016a, 2016c).

\subsection{Evaluation phase of the SMeHI method development process}

As discussed in Section 2.2.4, DSR artefacts can be evaluated using a number of approaches. We followed a three-stage approach in evaluating SMeHI.

First, we developed a number of scenarios around a hypothetical e-health interoperability project. This enabled us to assess the extent to which phases of SMeHI could be applied to arrive at the set of e-health standards for the scenarios. 
Figure 5 The outcome of applying SMEHI in the South African health context

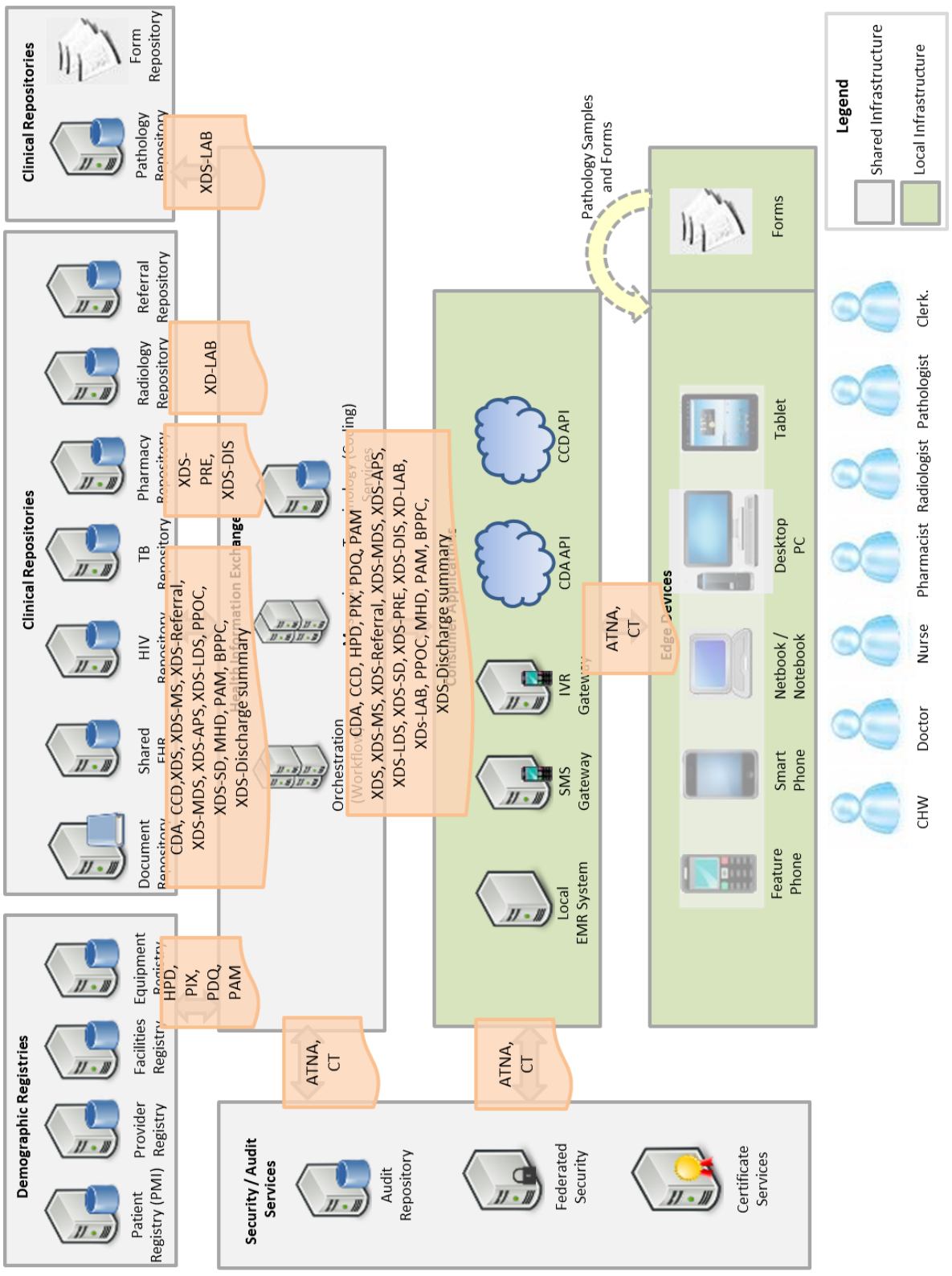


Thereafter, given the intended users of SMeHI, i.e., government agencies that recommend e-health standards to adopt and agencies responsible for the development of country-specific standards, we applied the method to a real-world context and used it to develop the South African national health normative standards framework for interoperability in eHealth (HNSF) (NDoH and CSIR, 2014). The HNSF was commissioned by the South African National Department of Health $(\mathrm{NDoH})$ to address one of ten priority areas identified in the country's eHealth Strategy 2012-2016, namely standards and interoperability $(\mathrm{NDoH}, 2012)$. Figure 5 provides a high-level view of the outcome of applying SMeHI in this context. A detailed discussion of the HNSF is, however, beyond the scope of this paper. Suffice to say that the HNSF was officially gazetted as a 'soft legislation' in Government Gazette 37583 (Government Notice 314) on 23 April 2014 (Motsoaledi, 2014).

SMeHI was also evaluated against the design objectives stated in Section 3.1. The method consists of five easy-to-follow phases. A phased approach to standards selection is beneficial in that it establishes a solid foundation for the derived standards and allows relevant stakeholders to be involved throughout the process. SMeHI also leans toward the use of IHE profiles, which contains relevant standards per profile, and provides guidelines on their implementation. Although the HL7 Version 3 suites (HL7, 2017), and ISO 13606 (ISO, 2008a, 2008b, 2009a, 2009b, 2010) standards are mature and capable of addressing interoperability requirements of many countries, they are not widely used globally due to their steep learning curve. IHE profiles on the other hand has gained wide acceptance in many countries and are freely available for public use. As such, SMeHI also meets the objective of ease of use by people with limited skills on e-health standards.

\subsection{Conclusion phase of the SMeHI method development process}

According to Vaishnavi and Kuechler (2015), the conclusion phase of a DSR process is characterised by a number of activities, including reporting and communication of research outcome to relevant audiences. It is also in this phase that researchers reflect on lessons learnt and identify contributions to the scientific body of knowledge.

Section 4 reflects on the research process by comparing SMeHI to the approaches described in Section 3.2.4. We also discuss our knowledge contributions to DSR paradigm.

\section{Discussion and reflection}

SMeHI is a generic method that could be used as-is, or adapted, to determine the sets of e-health standards to be adopted. SMeHI fits into what Purao (2002) defined as operational principles, i.e., artefacts that specify how to do things in a reproducible manner. Although SMeHI was targeted at African countries, any country, developed or developing, can use the method.

SMeHI has a number of similarities to the approaches described in Section 3.2.4, but it also has distinct features that are not evident in other approaches. For example, while the 'needs identification and business definition' phase in the Canadian approach is similar to phase 1 and phase 2 of SMeHI, there is no explicit description in the Canadian approach of how needs identification and business definition should be 
executed. In SMeHI, business needs are specified through use case scenarios, a technology-independent approach to requirement specification.

When compared to the European Commission standards selection approach, SMeHI has a distinct phase where interoperability objectives are identified. There is no explicit phase for the identification of interoperability objectives in the European Commission standards selection approach, although the 'use case definition and prioritisation' phase could support determination of interoperability objectives. SMeHI supports use case scenarios to describe healthcare processes, as does the European Commission approach.

$\mathrm{SMeHI}$ does not have a phase corresponding to the 'standards development and maintenance' phase in the Canadian approach, nor the 'profile development and maintenance' phase in the European Commission approach. This is because SMeHI is specifically targeted at African and other developing countries, where skills and expertise in e-health standards and/or profile development and maintenance are scarce, and the use of existing, well-defined and proven profiles would be more beneficial.

The only African country with publicly available information of its e-health standards adoption is Kenya. Even so, Kenya did not have any explicit process steps or phases guiding its selection of e-health standards. The decision of the standards to use was based on pre-defined functional requirements for EMR systems. The only similarity between $\mathrm{SMeHI}$ and the Kenyan approach is in the functional requirements. While the Kenyan approach is silent on how EMR functional requirements were arrived at, SMeHI supports the derivation of healthcare functions from the use case scenarios.

SMeHI also has some similarities to the CAMSS method, discussed in Section 2.3.2. Both methods were developed around use case scenarios, and are aimed at enabling interoperability (SMeHI e-health applications and CAMSS general-purpose ICTs). Both methods place emphasis on the involvement of relevant stakeholders in the process. However, there are also distinct differences between the two methods. CAMSS makes use of a panel of technical experts who assess the suitability of relevant standards that could meet a specific business need. SMeHI does not require this type of expertise. SMeHI relies of the use of IHE profiles, which have been tried and tested. The IHE profiles also contain detailed descriptions of how standards should be used and combined to address specific clinical requirements, and therefore have its own 'built-in technical experts'.

When compared to the component of what constitute DSR as proposed by Venable and Baskerville (2012), SMeHI fulfils the requirement of purposeful artefact. Its utility to guide the selection of e-health standards was demonstrated through application to a hypothetical scenarios and real-world context. SMeHI could also be seen as an 'invention' from the Venable and Baskerville (2012) perspective; in that SMeHI is an improvement to current multiple approaches to e-health standards selection. In terms of addressing a generalised problem type, $\mathrm{SMeHI}$ is a response to the call by the WHO (2014), which asked for guidance to LMICs on how to determine minimum set of standards to support interoperability. SMeHI also fulfilled the evaluation component identified by Venable and Baskerville (2012). As discussed in Section 3.3, we evaluated the utility of SMeHI using three approaches, first through descriptive evaluation, where we developed scenarios around a hypothetical e-health interoperability project. We also used the method in a real-world context to develop the South African HNSF (NDoH and CSIR, 2014). Lastly, SMeHI was assessed against, and found to meet, the design objectives specified in Section 3.1. 
SMeHI addresses the special needs of African countries by providing a phased approach to the selection of tried and tested standards-based IHE profiles. As stated in Section 3.2.5.2, the implementation of e-health standards to solve real-world interoperability problems requires the combination of several standards. This could lead to potential conflict between the standards. SMeHI does not require intended users to make decisions on which individual standards to combine, since IHE profiles define the precise manner in which HISs must combine standards when implementing a particular profile.

In addition, in Section 2.2.5 we indicated that knowledge in DSR can be conceptual, descriptive or prescriptive (Gaß et al., 2012; Gregor and Hevner, 2013; Iivari, 2007; van Aken, 2005). Van Aken (2004) laments the paucity of prescriptive research that is aimed at enhancing the relevance and applicability of research among academics. The knowledge contribution of our research is mainly of the prescriptive type, that is, how to determine the set of standards to enable interoperability between HISs. SMeHI also maps to the improvement quadrant of the Gregor and Hevner (2013) knowledge contribution framework. As discussed in Section 3.1, there is currently no unified approach to the selection of e-health standards. The research is therefore also an addition to current body of e-health research that makes use of the DSR paradigm. SMeHI is thus an improvement to the overall status quo.

\section{Conclusions}

Although the number of the method form DSR artefacts is increasing, few of the publications on these artefacts provide detailed discussions of the process followed to create the method artefact, in and of itself. When it comes to e-health research, it is even less common to find researchers using the DSR paradigm to develop artefacts. The research reported on in this paper presented a real-world application in the e-health systems development domain to develop the SMeHI method artefact, a generic method that guides the selection of e-health standards to support interoperability between HISs. The particular needs of Africa were taken into account when developing the method artefact. The paper provided a detailed discussion of the process we followed to develop the SMeHI artefact using DSR.

\section{Acknowledgements}

The authors wish to acknowledge the following individuals for their inputs and contributions during the development of the South African National Health Normative Standards Framework for Interoperability in eHealth and the triggering of the ideas that lead to the formulation of SMeHI: Derek Ritz, Rosemary Foster, Darelle van Greunen and Alida Veldsman.

The work presented in this paper was partially funded by both the National Research Foundation and the Council for Scientific and Industrial Research. 


\section{References}

Adebesin, F., Foster, R., Kotzé, P. and Van Greunen, D. (2013) 'A review of interoperability standards in e-health and imperatives for their adoption in Africa', South African Computer Journal, Vol. 50, pp.55-72.

Amrollahi, A., Ghapanchi, A. and Talaei-Khoei, A. (2014) 'From artefact to theory: ten years of using design science in information systems research', in Brown, A. and Rich, M. (Eds.): 13th European Conference on Research Methodology for Business and Management Studies (ECRM 2014), Academic Conferences \& Publishing International Ltd, Red Hook.

Antilope (2014) Refinement of Antilope Use Cases [online] http://www.antilope-project.eu/wpcontent/uploads/2013/05/D1.1_RefinementofAntilopeUseCases_v0.9g.pdf (accessed 22 July 2014).

Atalag, K., Kingsford, D., Paton, C. and Warren, J. (2010) 'Putting health record interoperability standards to work', Electronic Journal of Health Informatics, Vol. 5, No. 1 [online] http://www.ejhi.net/ojs/index.php/ejhi/article/view/100.

Australian Consortium for Classification Development (2017) ICD-10-AM/ACHI/ACS [online] https://www.accd.net.au/Icd10.aspx (accessed 29 September 2017).

Ayanso, A., Lertwachara, K. and Vachon, F. (2011) 'Design and behavioral science research in premier is journals: evidence from database management research', in Jain, H., Sinha, A.P. and Vitharana, P. (Eds.): Service-Oriented Perspectives in Design Science Research, Springer, Heidelberg.

Bender, D. and Sartipi, K. (2013) 'HL7 FHIR: an agile and restful approach to healthcare information exchange', in Rodrigues, P.P., Pechenizkiy, M., Gama, J., Cruz-Correia, R., Liu, J., Traina, A., Lucas, P. and Soda, P. (Eds.): Proceedings of the 26th IEEE International Symposium on Computer-Based Medical Systems, IEEE.

Benson, T. (2010) Principles of Health Interoperability HL7 and SNOMED, Springer-Verlag, London.

Bucher, T. and Winter, R. (2008) 'Dissemination and importance of the 'method' artifact in the context of design research for information systems', in Vaishnavi, V. and Baskerville, R. (Eds.): 3rd International Conference on Design Science Research in Information Systems and Technology (DESRIST 2008), Georgia State University, Atlanta.

Canada Health Infoway (2012) Pan-Canadian Standards Decision Making Process, Infoway Standards Collaborative, Toronto [online] https://infocentral.infoway-inforoute.ca/images/ Infoway/Standards/DMP_Update_20120116.pdf. (accessed 16 April 2014).

Canada Health Infoway (2017) Pan-Canadian LOINC Observation Code Database ( $p C L O C D$ ) Nomenclature Standard [online] https://infocentral.infoway-inforoute.ca/en/standards/ inventory/pclocd (accessed 20 September 2017).

Canadian Institute for Health Information (CIHI) (2017) ICD-10-CA (International Statistical Classification of Diseases and Related Health Problems (10th Revision), Canada, Ottawa [online] https://www.cihi.ca/en/submit-data-and-view-standards/codes-and-classifications/icd10-ca (accessed 20 October 2017).

CEN, CENELEC and ETSI (2009) eHealth-INTEROP Report in Response to eHealth Interoperability Standards Mandate, NEN Healthcare, Delft [online] http://www.ehealthinterop.eu.

Department of Defence Systems Management College (2001) Systems Engineering Fundamentals, Defense Acquisition University Press, Virginia.

eHealth Ontario (2013) Standards Selection Guide, Ontario [online] https://www.ehealthontario.on.ca/images/uploads/pages/documents/eHealth_Standards_Select ion_Framework_en.pdf. (accessed 11 July 2016). 
European Commission (2007) M/403 Mandate to the European Standardisation Organisations CEN, CENELEC and ETSI in the Field of Information and Communication Technologies, Applied to the Domain of Ehealth, European Commission Enterprise and Industry Directorate-General, Brussels [online] http:/ec.europa.eu/growth/tools-databases/ mandates/index.cfm?fuseaction=search.detail\&id=363\# (accessed 29 September 2017).

European Commission (2012a) Detailed CAMSS Process, IDABC-CAMMS [online] https://webgate.ec.europa.eu/fpfis/mwikis/idabc-camss/index.php/Detailed_

CAMSS_Process\#Adoption_Step (accessed 13 January 2016).

European Commission (2012b) Introduction to CAMSS, IDABC-CAMMS [online] https://webgate.ec.europa.eu/fpfis/mwikis/idabc-camss/index.php/Main_Page (accessed 11 January 2016).

European Commission (2014) The Guide: Using Standards for ICT Procurement [online] http://www.openictprocurement.eu/introduction-background/ (accessed 11 January 2016).

European Commission (2015) Achieving a Modern ICT Standardisation Policy [online] https://ec.europa.eu/isa2/actions/achieving-modern-ict-standardisation-policy_en (accessed 11 January 2016).

Gaß, O., Koppenhagen, N., Biegel, H., Medche, A. and Müller, B. (2012) 'Anatomy of knowledge bases used in design science research: a literature review', in Peffers, K., Rothenberger, M. and Kuechler, B. (Eds.): 7th International Conference on Design Science Research in Information Systems and Technology, DERIST 2012, Springer-Verlag, Las Vegas.

Gibbons, P., Arzt, N., Burke-Beebe, S., Chute, C., Dickinson, G., Flewelling, T., Jepsen, T., Kamens, D., Larson, J., Ritter, J., Rozen, M., Selover, S. and Stanford, J. (2007) Coming to Terms: Scoping Interoperability for Health Care [online] https://www.hln.com/assets/pdf/ Coming-to-Terms-February-2007.pdf (accessed 7 May 2017).

Global Inventory of Statistical Standards (2010) Statistical Data and Metadata Exchange - Health Domain (SDMX-HD) [online] https://unstats.un.org/unsd/iiss/Statistical-Data-and-MetadataExchange-Health-Domain-SDMX-HD.ashx (accessed 20 October 2017).

Goldkuhl, G. (2002) 'Anchoring scientific abstractions - ontological and linguistic determination following socio-instrumental pragmatism', European Conference on Research Methods in Business and Management (ECRM 2002), Reading.

Gregg, D.G., Kulkarni, U.R. and Vinze, A. (2001) 'Understanding the philosophical underpinnings of software engineering research in information systems', Information Systems Frontiers, Vol. 3, No. 2, pp.169-183.

Gregor, S. and Hevner, A. (2013) 'Positioning and presenting design science research for maximum impact', MIS Quarterly, Vol. 37, No. 2, pp.337-355.

Gregor, S. and Jones, D.P. (2007) 'The anatomy of a design theory', Journal of the Association for Information Systems, Vol. 8, No. 5, pp.313-334.

Health Information and Quality Authority (HIQA) (2011) Developing National eHealth Interoperability Standards for Ireland: A Consultation Document, Dublin [online] https:/www.hiqa.ie/sites/default/files/2017-01/eHealth-Interoperability-Consultation.pdf.

Health Information and Quality Authority (HIQA) (2012) Guidance on Messaging Standards for Ireland, Dublin [online] https://www.hiqa.ie/sites/default/files/2017-01/Guidance-onMessaging-Standards.pdf.

Health Information and Quality Authority (HIQA) (2013) Guidance on Classification and Terminology Standards for Ireland, Dublin [online] https://www.hiqa.ie/system/files/ Guidance-on-Terminology-Standards-for-Ireland_0.pdf..

Health Level Seven International (HL7) (2013a) CDA Release 2 [online] http://www.hl7.org/ implement/standards/product_brief.cfm?product_id $=7$ (accessed 20 October 2017).

Health Level Seven International (HL7) (2013b) HL7 Version 2 Product Suite, Michigan. [online] http://www.hl7.org/implement/standards/product_brief.cfm?product_id=185 (accessed 20 October 2017). 
Health Level Seven International (HL7) (2017) HL7 Version 3 Product Suite, Michigan [online] https://www.hl7.org/implement/standards/product_brief.cfm?product_id=186 (accessed 20 October 2017).

Hevner, A.R. and Chatterjee, S. (2010) Design Science Research in Information Systems: Theory and Practice, Springer Science+Business Media, New York.

Hevner, A.R., March, S.T., Park, J. and Ram, S. (2004) 'Design science in information systems research', MIS Quarterly, Vol. 28, No. 1, pp.75-105.

Iivari, J. (2007) 'A paradigmic analysis of information systems as a design science', Scandinavian Journal of Information System, Vol. 19, No. 2, pp.39-64.

Integrating the Healthcare Enterprise (IHE) (2016a) Case Studies, Illinois [online] http://www.ihe.net/User_Success_Stories/ (accessed 20 October 2017).

Integrating the Healthcare Enterprise (IHE) (2016b) Cross-Enterprise Document Sharing for Imaging, Illinois [online] http://wiki.ihe.net/index.php/Cross-enterprise_Document_Sharing for_Imaging (accessed 20 October 2017).

Integrating the Healthcare Enterprise (IHE) (2016c) IHE Connectathon: A Unique Testing Opportunity, Illinois [online] https://ihe.net/connectathon.aspx (accessed 20 October 2017).

Integrating the Healthcare Enterprise (IHE) (2016d) IHE International, Illinois [online] http://www.ihe.net/ (accessed 20 October 2017).

International Organization for Standardization (ISO) (2008a) ISO 13606-1:2008 - Electronic Health Record Communication - Part 1: Reference Model [online] https://www.iso.org/ obp/ui/\#iso:std:iso:13606:-1:ed-1:v1:en (accessed 20 October 2017).

International Organization for Standardization (ISO) (2008b) ISO 13606-2:2008 - Electronic Health Record Communication - Part 2: Archetype Interchange Specification, Geneva [online] https://www.iso.org/obp/ui/\#iso:std:iso:13606:-2:ed-1:v1:en (accessed 20 October 2017).

International Organization for Standardization (ISO) (2009a) ISO 13606-3:2009 - Electronic Health Record Communication - Part 3: Reference Archetypes and Term Lists, Geneva [online] https://www.iso.org/obp/ui/\#iso:std:iso:13606:-3:ed-1:v1:en (accessed 20 October 2017).

International Organization for Standardization (ISO) (2009b) ISO 13606-4:2008 - Electronic Health Record Communication - Part 4: Security, Geneva [online] http://www.iso.org/iso/ home/store/catalogue_tc/catalogue_detail.htm?csnumber $=50121 \&$ commid $=54960$ (accessed 20 October 2017).

International Organization for Standardization (ISO) (2010) ISO 13606-5:2010 - Electronic Health Record Communication - Interface Specification, Geneva [online] https://www.iso.org/ obp/ui/\#iso:std:iso:13606:-5:ed-1:v1:en (accessed 20 October 2017).

International Telecommunication Union (ITU) (2012) E-Health Standards and Interoperability, ITU-T Technology Watch, Geneva [online] https://www.itu.int/dms_pub/itu-t/oth/23/01/ T23010000170001PDFE.pdf.

Kotzé, P., van der Merwe, A. and Gerber, A. (2015) 'Design science research as research approach in doctoral studies', AMCIS 2015 Proceedings, AIS, Puerto Rico.

Kun, L. (2007) 'Interoperability: 'the cure for what ails us', IEEE Engineering in Medicine and Biology Magazine, Vol. 26, No. 1, pp.87-90.

Kunene, K.N. and Weistroffer, H.R. (2006) 'Design of a method to integrate knowledge discovery techniques with prior domain knowledge for better decision support', in Chatterjee, S. and Hevner, A. (Eds.): Proceedings of the 1st International Conference on Design Science Research in Information Systems and Technologies (DESRIST 2006), Claremont Graduate University, Claremont.

Lehto, T. (2012) 'Designing persuasive health behavior change interventions', in Wickramasinghe, N., Bali, R., Suomi, R. and Kirn, S. (Eds.): Critical Issues for the Development of Sustainable E-health Solutions, Springer, Boston. 
March, S.T. and Smith, G.F. (1995) 'Design and natural science research on information technology', Decision Support Systems, Vol. 15, No. 4, pp.251-266.

Mccormick, M. (2011) Business Use-Case Modeling, MPCS, Washington [online] http://www.mccormickpcs.com/images/Business_Use_Case_Modeling.pdf (accessed 08 November 2013).

Medical Imaging and Technology Alliance (NEMA) (2017) DICOM Digital Imaging and Communication in Medicine, Rosslyn [online] http://dicom.nema.org/standard.html (accessed 20 October 2017).

Ministry of Medical Services and Ministry of Public Health and Sanitation (2010) Standards and Guidelines for Electronic Medical Record Systems in Kenya [online] https://www.ghdonline.org/uploads/Standards_and_Guidelines_for_Electronic_Medical_Reco rd_Systems.pdf.

Modell, M. (2007) A Professional's Guide to Systems Analysis, McGraw-Hill, New York.

Motsoaledi, A. (2014) National Health Act (61/2003): National Health Normative Standards Framework for Interoperability in eHealth, Government Gazette 37583 (Government Notice 314).

Myers, M.D. and Venable, J.R. (2014) 'A set of ethical principles for design science research in information systems', Information and Management, Vol. 51, No. 6, pp.801-809.

Peffers, K., Tuunanen, T., Rothenberger, M.A. and Chatterjee, S. (2008) 'A design science research methodology for information systems research', Journal of Management Information System, Vol. 24, No. 3, pp.45-77.

Purao, S. (2002) Design Research in the Technology of Information Systems: Truth or Dare, Working Paper, Georgia State University, Atlanta.

Regensief Institute (2017) LOINC [online] https://loinc.org/ (accessed 20 October 2017).

Ryan, A. (2006) 'Towards semantic interoperability in healthcare: ontology mapping from SNOMED-CT to HL7 Version 3', in Orgun, M.A. and Meyer, T. (Eds.): Proceedings of the Second Australasian Workshop on Advances in Ontologies, Vol. 72, Australian Computer Society, Inc, Hobart.

Serrano-Santoyo, A. and Rojas-Mendizabal, V. (2014) 'E-health standardization challenges in emerging economies: the case of Mexico', Proceedings of the 2014 ITU Kaleidoscope Academic Conference: Living in a Converged World - Impossible without Standards?, IEEE.

Snomed International (2017) SNOMED CT: The Global Language of Healthcare, International Health Terminology Standards Development Organization [online] http://www.snomed.org/ snomed-ct (accessed 29 September 2017).

South African National Department of Health $(\mathrm{NDoH})$ (2012) eHealth Strategy South Africa 2012-2016, Pretoria [online] http://www.hst.org.za/publications/NonHST\%20Publications/ eHealth_Strategy_South_Africa_2012-2016.pdf.

South African National Department of Health $(\mathrm{NDoH})$ and Council for Scientific and Industrial Research (CSIR) (2014) South African National Health Normative Standards Framework for Interoperability in eHealth: Complete Version, Pretoria [online] http://hufee.meraka.org.za/ Hufeesite/staff/the-hufee-group/paula-kotze-1/hnsf-complete-version.

The Rockefeller Foundation (2010) From Silos to Systems: An Overview of eHealth's Transformative Power, The Rockefeller Foundation, New York [online] http://en.esacproject.net/sites/intranet.esacproject.net/files/e331d255-059f-4fc6-b8145938f8ee017e-rf.silos_1-13.pdf.

Thorp, J. (2010) 'Europe's e-health initiatives: an overview of European interoperability initiatives', Journal of AHIMA, September, pp.56-58.

Vaishnavi, V. and Kuechler, B. (2015) Design Science Research in Information Systems [online] http://www.desrist.org/design-research-in-information-systems/ (accessed 20October 2017). 
van Aken, J.E. (2004) 'Management research based on the paradigm of the design sciences: the quest for field-tested and grounded technological rules', Journal of Management Studies, Vol. 41, No. 2, pp.219-246.

van Aken, J.E. (2005) 'Management research as a design science: articulating the research products of mode 2 knowledge production in management', British Medical Journal, Vol. 16, No. 1, pp.19-36.

Venable, J. and Baskerville, R. (2012) 'Eating our own cooking: toward a more rigorous design science of research methods', Electronic Journal of Business Research Methods, Vol. 10, No. 2, pp.141-153.

Verbrugge, B. (2016) Best Practice, Model, Framework, Method, Guidance, Standard: Towards a Consistent Use of Terminology Revised [online] http://www.vanharen.net/blog/van-harenpublishing/best-practice-model-framework-method-guidance-standard-towards-consistent-useterminology/ (accessed 20 October 2017).

Walker, J., Pan, E., Johnston, D., Adler-Milstein, J., Bates, D. and Middleton, B. (2005) 'The value of health care information exchange and interoperability', Health Affairs, January, w5, pp.10-18.

World Health Organization (WHO) (2003) International Classification of Primary Care, 2nd ed., ICPC-2, Geneva [online] http://www.who.int/classifications/icd/adaptations/icpc2/en/.

World Health Organization (WHO) (2012) WHO Forum on Health Data Standardization and Interoperability, Geneva [online] http://www.who.int/ehealth/ WHO_Forum_on_HDSI_Report.pdf.

World Health Organization (WHO) (2014) Joint Inter-Ministerial Policy Dialogue on eHealth Standardization and Second WHO Forum on eHealth Standardization and Interoperability, Geneva [online] http://www.who.int/ehealth/events/final_forum_report.pdf.

World Health Organization (WHO) (2016a) ICD-10 Version: 2016, Geneva [online] http://apps.who.int/classifications/icd10/browse/2016/en (accessed 20 October 2017).

World Health Organization (WHO). (2016b) International Classification of Diseases (ICD), Geneva [online] http://www.who.int/classifications/icd/en/ (accessed 20 October 2016).

World health Organization and International Telecommunication Union (WHO and ITU) (2012) National eHealth Strategy Toolkit, Geneva [online] http://apps.who.int/iris/bitstream/10665/ 75211/1/9789241548465_eng.pdf. 